\title{
Characterization and antimicrobial resistance of clinical isolates of enterococci in tertiary care hospital in eastern Nepal
}

\author{
HP Nepal ${ }^{1}$, B Khanal ${ }^{2}$, A Acharya ${ }^{1}$ \\ 'Department of Microbiology, Chitwan Medical College, Bharatpur, Nepal \\ ${ }^{2}$ Department of Microbiology, BP Koirala Institute of Health Sciences, Dharan, Nepal
}

\begin{abstract}
Background: Enterococci, commensal flora of humans and animals, can cause variety of infections. They may pose therapeutic challenge due to their resistance to number of antimicrobial agents. Knowledge about the prevalence of their different species and resistance pattern is quite essential for the selection of the appropriate therapy for management of enterococcal infection. Objective: to characterize and determine resistance pattern of enterococcal isolates. Methods: Enterococci isolated from the clinical specimens submitted to the microbiology unit of clinical laboratory services (CLS), BP Koirala Institute of Health Sciences (BPKIHS) were studied. Characterization and determination of antimicrobial resistance were done by standard microbiological technique. Results: Among the 110 isolates studied, 9 different species of Enterococcus were recovered: E. faecalis $(66.36 \%)$, E. faecium $(22.73 \%)$, E. saccharolyticus $(4.54 \%)$, E. cecorum $(1.82 \%)$, E. avium $(0.91 \%)$, E. dispar $(0.91 \%)$, E. gallinarum $(0.91 \%)$, E. hirae $(0.91 \%)$ and E. mundtii $(0.91 \%)$. The isolates were obtained from various clinical specimens from patients of different ages. The resistance observed for different antimicrobials tested was: ampicillin (95.45\%), chloramphenicol $(14.55 \%)$, ciprofloxacin $(51.82 \%)$, erythromycin $(54.54 \%)$, gentamicin $(53.63 \%)$, nitrofurantoin $(7.55 \%)$, and tetracycline $(58.18 \%)$. No isolate exhibited resistance to vancomycin. Conclusion: Different species of enterococci causing wide spectrum of infections are common in our set up. They exhibited varying frequencies of resistance to almost all the antimicrobials tested. In the context of rising concern about the emergence of high level gentamicin resistant enterococci and vancomycin resistant enterococci, it is recommended to perform screening test and MIC determination to confirm resistance of the local strains to these antimicrobials.
\end{abstract}

Keywords: enterococci, BPKIHS, characterization, antimicrobial resistance

\section{Introduction}

Enterococci are gram-positive cocci that occur singly, in pairs or as short chains. ${ }^{1}$ They are indigenous flora of the intestinal tract, oral cavity and the genitourinary tract of the humans and animals but have become important opportunistic pathogens, especially in hospitalized patients. ${ }^{2}$

Address for correspondence

Dr. Hari Prasad Nepal

Asistant Professor, Department of Microbiology,

Chitwan Medical College, Bharatpur, Nepal

Email: drharinepal@gmail.com
Enterococci have gained much attention in the recent years not only because of their ability to cause serious infections like endocarditis, bacteremia, intraabdominal and urinary tract infection (UTI), but also because of their resistance to a vast array of antimicrobial drugs, including cell-wall active agents, all commercially available aminoglycosides, penicillin and ampicillin, and vancomycin., ${ }^{3,4}$

Since the inception of separate genus Enterococcus, more than 30 different species of enterococci have been identified ${ }^{5}$, of which Enterococcus faecalis and Enterococcus faecium accounts for up to $90 \%$ of 
clinical isolates belonging to this genus. ${ }^{2}$ Nevertheless, the incidence of other species of enterococci from clinical sources shows an alarming increase with the properties of intrinsic resistance to several antibiotics including beta-lactams and glycopeptides. ${ }^{6,7}$ But the incidence of non-faecalis and non-faecium enterococci is underestimated because of frequent misidentification ${ }^{8}$. Having knowledge of prevalence of the different species of enterococci and resistance pattern help us to select the appropriate therapy for management of enterococcal infection Thus, present study aimed to characterize the clinical isolates of Enterococcus prevalent in our set up and determine their resistance to the most commonly used antimicrobials in BPKIHS, a tertiary care hospital of eastern Nepal

\section{Methods}

A total of 110 isolates of enterococci, recovered during a period of one year from January 2008 to December 2008 from various clinical specimens comprising of urine, blood, pus, aspirates, wound swab, high vaginal swab, catheter tip, cerebrospinal fluid, peritoneal fluid, sputum, tissues and corneal scrapings coming to CLS for culture and sensitivity were studied.

All the specimens except urine were inoculated onto blood, MacConkey agar and chocolate agar (whenever necessary), whereas urine was plated onto cystine lactose electrolyte deficient (CLED) medium. ${ }^{9}$ The media after inoculation were incubated aerobically at $37^{\circ} \mathrm{C}$ for $24-48$ hours. Brain Heart Infusion (BHI) broth was used as primary culture medium for all blood culture samples. ${ }^{9}$ After 24-48 hours of incubation, subcultures were performed on to blood and MacConkey agar as for inoculation of other samples. ${ }^{9}$ Growth was recorded on the following day.

Presumptive identification of Enterococcus species was based on the colony characteristics, type of hemolysis, gram reactions and catalase negativity. All cultures where Enterococcus species were grown as pure or predominant organisms were considered for further characterization. Information regarding patient's name, age, gender, origin (OPD, emergency or ward) and the type of sample collected was recorded. Characterization of enterococci was carried out using recommended tests. ${ }^{10,11}$
Antimicrobial susceptibility test was performed on Mueller Hinton blood agar medium by the standard disk diffusion method recommended by the Clinical Laboratory Standards Institute (CLSI) guidelines ${ }^{12}$ against ampicillin (10 ìg), chloramphenicol (30 ìg), ciprofloxacin (5 ìg), erythromycin (15 ìg), gentamicin (10 ig), nitrofurantoin (300 ig), tetracycline (30 ig) and vancomycin (30 ig). Staphylococcus aureus ATCC 25923 and Enterococcus faecalis ATCC 29212 were used as controls and tested daily along with the test strains.

\section{Results}

Among the 110 isolates of Enterococcus, majority $(67.27 \%)$ were obtained from patients admitted to the various wards, $17.27 \%$ from patients brought to emergency department and $15.46 \%$ from patients attending to outpatient departments. Highest number of the isolates was obtained from the gynecology ward $(30.91 \%)$ followed by surgery ward $(19.09 \%)$ (Table 1).

\section{Table 1: Number of isolates from various} departments

\begin{tabular}{|l|c|c|}
\hline $\begin{array}{l}\text { Place of origin of } \\
\text { samples }\end{array}$ & $\begin{array}{c}\text { No. of } \\
\text { isolates }\end{array}$ & $\begin{array}{c}\text { Percentage } \\
\text { of isolates }\end{array}$ \\
\hline $\begin{array}{l}\text { Outpatient departments } \\
\text { (OPDs): }\end{array}$ & 17 & 15.64 \\
\hline GOPD & 6 & 5.45 \\
\hline Surgery & 5 & 4.55 \\
\hline Gynecology & 5 & 4.55 \\
\hline Dermatology & 1 & 0.91 \\
\hline Emergency & 19 & 17.27 \\
\hline Wards: & 74 & 67.27 \\
\hline Gynecology & 34 & 30.91 \\
\hline Surgery & 21 & 19.09 \\
\hline Pediatrics & 10 & 9.09 \\
\hline Medicine & 6 & 5.45 \\
\hline Orthopedics & 2 & 1.82 \\
\hline ICU & 1 & 0.91 \\
\hline Total & 110 & 100 \\
\hline
\end{tabular}

Isolates obtained from females and males were $62.73 \%$ and $37.27 \%$ respectively. Table 2 displays the age wise distribution of the enterococcal isolates, the highest percentage $(26.36 \%$ ) being obtained from the children below 10 years of age. 
Table 2: Distribution of isolates in various age groups

\begin{tabular}{|c|c|c|}
\hline Age group & $\begin{array}{l}\text { No. of } \\
\text { isolates }\end{array}$ & $\begin{array}{l}\text { Percentage } \\
\text { of isolates }\end{array}$ \\
\hline Up to 10 years & 29 & 26.36 \\
\hline a. $<1$ month & 16 & 14.54 \\
\hline b. $>1$ month- 12 months & 8 & 7.27 \\
\hline c. 1 year- 5 years & 3 & 2.73 \\
\hline d. $6-10$ years & 2 & 1.82 \\
\hline $11-20$ years & 9 & 8.18 \\
\hline $21-30$ years & 19 & 17.27 \\
\hline $31-40$ years & 11 & 10 \\
\hline $41-50$ years & 15 & 13.64 \\
\hline $51-60$ years & 10 & 9.09 \\
\hline$>60$ years & 17 & 15.45 \\
\hline
\end{tabular}

Among the various specimens from which the isolates (i.e., total 110) were obtained, majority $(48.18 \%)$ was from urine followed by blood $(18.18 \%)$. The details are given in figure 1 .

Figure 1: Distribution of isolates in various specimens

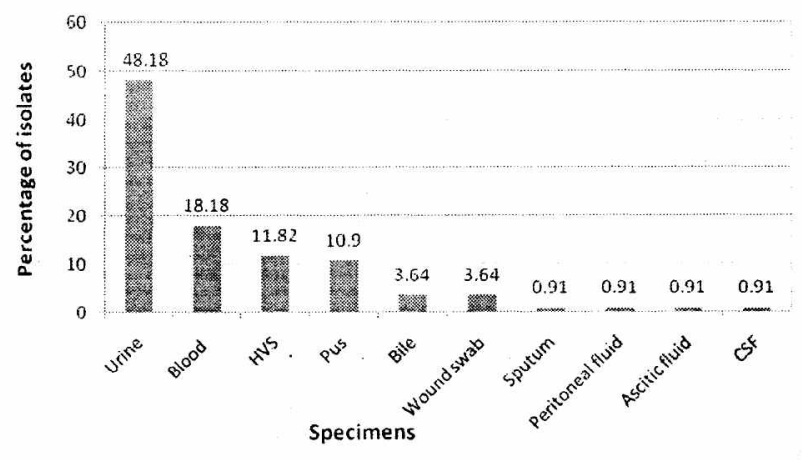

\section{Species identification}

After characterization with a set of biochemical tests, majority $(66.36 \%)$ of the isolates were identified as E. faecalis. E. faecium ranked the second position $(22.73 \%)$ while E. saccharolyticus and E. cecorum the third $(4.54 \%)$ and the fourth $(1.82 \%)$ ones respectively. Other species obtained as single isolate $(0.91 \%)$ each were the E. avium, E. dispar, E. gallinarum, E. hirae and E. mundtii.

\section{Antimicrobial susceptibility}

Antimicrobial susceptibility, determined by KirbyBauer disk diffusion method, of the isolates is presented in the following table (Table 3). The rate of resistance was highest (95.45) for Ampicillin while it was none for vancomycin.

\section{Discussion}

Enterococci are capable of causing infections both in and out of hospital setting, and it was previously thought that most infections due to these organisms were endogenously acquired from the patient's own flora. ${ }^{13}$ However, most enterococcal infections occur in hospitalized patients or in patients undergoing therapy such as peritoneal or hemodialysis, and the organisms causing such infections often appear to be exogenously acquired ${ }^{13}$. Of the 110 isolates in the present study, majority $(67.27 \%)$ were obtained from patients admitted to various wards. The centers for Disease Control and Prevention's National Nosocomial Infection Surveillance Survey ${ }^{14}$ also listed the Enterococcus as the third most common organism recovered from nosocomial infections in 1990 to 1992, following E. coli and Staphylococci. Several factors appear to be involved in the emergence of enterococci as important nosocomial pathogens, including the multiple resistance characteristics of these organisms, heavy use of antimicrobial agents to which these organisms are resistant, use of mechanically compromising devices such as intravascular lines and urinary catheters, and increasing numbers of seriously ill and debilitated patients in hospitals ${ }^{15}$. Although majority of the isolates in the present study were from the in-patients we did not make an attempt to determine if they were of nosocomial origin.

Female predominance $(63 \%)$ over males seen in our study corresponds to the findings of McCarthy et $\mathrm{al}^{16}(56.14 \%)$. Greater vulnerability to acquire urinary tract infection and pelvic infection due to anatomic position of urethra and genital tract might have played a role for predominant female infection by this organism.

Our study has shown the isolation of enterococci from all the age groups, ranging from newborn baby to an old of 82 years. However, highest percentage (26.36\%) of enterococcal isolates was obtained from the children below 10 years of age, followed by the people over 60 years $(15.45 \%)$. The isolation pattern of the organism in our study is similar to that observed by Low et al ${ }^{17}$ who also revealed the distribution of the isolates in the wide range of ages ( 1 month to 96 years). Underdeveloped immunity in the children and impaired immunity in the old people are the important predisposing factors for acquiring enterococcal infection in these two extreme ages. 
Of the total isolates under our study, majority $(48.18 \%)$ were recovered from urine, the findings being similar to that observed in Kuwait ${ }^{18}$ and India. ${ }^{19}$ Urinary tract infections are the most common type of clinical illness produced by enterococci, and urine cultures are the most frequent sources of enterococci in the clinical microbiology laboratory. ${ }^{20}$ Most enterococcal urinary tract infections are nosocomial and are associated with urinary catheterization and/ or instrumentation. ${ }^{21,22}$

Enterococcal bacteremia is also common type of infection and enterococci are the third leading cause of nosocomial bacteremia. ${ }^{1}$ Isolation rate of the organism from blood culture differed from study to study. Mathur et $\mathrm{al}^{19}$ reported $38 \%$ isolates being recovered from blood culture whereas Vandamme et $\mathrm{al}^{23} \mathrm{did} 16.7 \%$. In the present study, the isolation rate of enterococci from bacteremia was $18.8 \%$.

Intra-abdominal and pelvic wound infections are the commonly encountered enterococcal infections. ${ }^{1}$ In our study, $11.82 \%$ isolates were obtained from high vaginal swab, $10.90 \%$ from pus, $3.64 \%$ from bile and $0.91 \%$ isolate each was from peritoneal and ascitic fluid culture. Regarding isolation of the organism from these sources, our results are similar to the literature reports from other places. A study from Kuwait ${ }^{18}$ reported $9.1 \%$ isolates from high vaginal swab while the other from Belgium ${ }^{23}$ documented the isolation rate of $5.9 \%$ from pus, $4.2 \%$ from bile and $2.5 \%$ from abdominal or peritoneal fluids.

Enterococci are being recovered from wound infections at increasing rates, probably the result of increased antibiotic usage and emerging resistance among these organisms. ${ }^{1}$ In the present study, 3.63\% isolates were recovered from wound swab, the isolation rate being lower than the findings of Belgian study $(37.9 \%)^{23}$ and Kuwaitian study $(11.0 \%){ }^{18}$

Enterococcal infections of the respiratory tract or the central nervous system may occur, but are rare ${ }^{1}$. One isolate each $(0.91 \%)$ was obtained from sputum and CSF in our study. Almost similar rate of isolation from bronchial or tracheal fluids was observed by Vandamme et al (2.1\%). ${ }^{23}$

In this study, 9 different species of enterococci were recovered: Enterococcus faecalis (66.36\%), Enterococcus faecium (22.73\%), Enterococcus saccharolyticus (4.54\%), Enterococcus cecorum (1.82\%), Enterococcus avium (0.91\%),
Enterococcus dispar (0.91\%), Enterococcus gallinarum (0.91\%), Enterococcus hirae (0.91\%) and Enterococcus mundtii $(0.91 \%)$. E. faecalis and E. faecium, together, accounted for $89.09 \%$ of the total isolates whereas only $10.91 \%$ isolates were identified as members of other species of Enterococcus. The findings of the present study are in agreement with previous reports, ${ }^{24,25}$ which point to E. faecalis as the main species involved in human infection, followed by E. faecium.

Despite the recent availability of many new classes of antimicrobial agents, enterococci continue to pose a therapeutic problem. This is due to intrinsic as well as acquired resistance of the organism to the various groups of antibiotics. The various intrinsic (inherent) traits expressed by enterococci include resistance to semisynthetic penicillinase resistant penicillins, cephalosporins, low levels of aminoglycosides, and low levels of clindamycin. ${ }^{2}$ Examples of acquired resistance include resistance to chloramphenicol, erythromycin, high levels of clindamycin, tetracycline, high levels of aminoglycosides, penicillin by means of penicillinase, fluoroquinolones, and vancomycin. ${ }^{2}$ Ampicillin or penicillin remain the antibiotics of choice for treating enterococcal infections such as urinary tract infections, peritonitis, and wound infections that do not require the bactericidal treatment. ${ }^{13}$ Highest $(95.45 \%)$ rate of resistance has been observed for Ampicllin among all the antimicrobials tested in our studies. The rate is much higher than the observation of Coleri et al $(8.7 \%)^{26}$ and Mathur et al $(66 \%){ }^{22}$ McCarthy et $\mathrm{al}^{16}$ noted in early 1991 that only 3\% of all enterococci isolated in their lab were ampicillin resistant, and that had later risen to $14 \%$ in 1994 . A prolonged hospital stay and exposure to multiple antimicrobial agents, often in combination, were associated with colonization or infection with ARE. ${ }^{16}$ The prolonged hospital stay may reflect the fact that many of the patients colonized or infected with ARE had complicated and lengthy hospitalizations that required the use of intensive antimicrobial therapy. ${ }^{16}$ This could then lead to colonization and subsequent infection with ARE as a result of antimicrobial pressure. ${ }^{16}$

Most strains of enterococci (90-96\% in most centers) remain susceptible to nitrofurantoin, and this agent has been used successfully to treat enterococcal urinary tract infections. ${ }^{13}$ In our study, resistant percentage of the 53 urinary isolates tested against 
nitrofurantoin was $7.55 \%$. Our findings are in close agreement with the observation of Moellering RC $\mathrm{Jr}^{13}$ and Azevedo et al. ${ }^{27}$ The more interesting finding in the current study was that none of the isolates of E. faecalis was resistant to nitrofurantoin.

We have observed chloramphenicol resistance as $14.55 \%$. The lower resistance rate compared to the previous study ${ }^{28}$ may be due to minimal use and low exposure of this antimicrobial agent in our hospital environment.

Ciprofloxacin, considered to have only modest activity against enterococci ${ }^{29}$, is not used as a drug of first choice but has been successfully employed in the treatment of enterococcal urinary tract infections. Resistance to ciprofloxacin was found to be $51.82 \%$ in our study. But the rate of resistance reported differed from place to place: $22.6 \%$ in Brazil ${ }^{27}, 40 \%$ in Kuwait ${ }^{18}$ and $88 \%$ in India. ${ }^{19}$

In the present study, resistance observed for Erythromycin and tetracycline was $54.54 \%$ and $58.18 \%$ respectively. Our results are in close agreement with the previous reports. ${ }^{18,27}$

Low-level resistance to aminoglycosides is an inherent property of enterococci ${ }^{2}$. This is due to decreased ability of these agents to penetrate through the outer cell envelope of enterococci, a phenomenon that can be overcome with the addition of an appropriate cell wall-active agent resulting in synergistic killing of enterococci. ${ }^{13}$ In the current study, $53.63 \%$ of the isolates were found to be gentamicin resistant, whereas $14.55 \%$ were gentamicin intermediate. The rate of resistance seen in this study is lower than $76.78 \%$ of resistance observed in Pakistan. ${ }^{30}$

Vancomycin resistant enterococci (VRE) may cause a range of infections associated with high mortality. The emergence of VRE is a cause for concern because of the limited therapeutic options for treating serious infections and because of their potential to transfer vancomycin-resistance genes to other organisms, such as methicillin-resistant Staphylococcus aureus (MRSA). ${ }^{17}$ Varying rate of resistance has been reported from place to place: $1 \%$ in northern India ${ }^{19}, 2.6 \%$ in Kuwait $^{18}$ and $17.4 \%$ in South India ${ }^{8}$. Though, VRE were not observed in our study, significant number of isolates $(10 \%)$ demonstrated intermediate susceptibility which may indicate their impending emergence of resistance to vancomycin.

\section{Conclusion}

Different species of enterococci causing wide spectrum of infections are common in our set up. They exhibited varying frequencies of resistance to almost all the antimicrobials tested. In the context of rising concern about the emergence of high level gentamicin resistant enterococci and vancomycin resistant enterococci, it is recommended to perform screening test and MIC determination to confirm resistance of the local strains to these antimicrobials.

\section{Acknowledgment}

We would like to thank all the patients from whom the specimens were obtained. We are also thankful to all faculty members, post graduate students, and the staffs of Microbiology department for their help and cooperation to conduct this study.

\section{References}

1. Facklam RR, Teixeira LM. Enterococcus. In: Collier L, Balows A, Sussman M, editors. Topley $\&$ Wilson's Microbiology and Microbial Infections. $9^{\text {th }}$ ed. Vol II. London: Arnold; 1998. p. 669-82.

2. Murray BE. The life and times of enterococci. Clin Microbial Rev 1990; 3: 46-65.

3. Moellering RC. Emergence of enterococci as a significant pathogen. Clin Infect Dis 1992; 14: 1173-78.

4. Murray BE. Diversity among multidrug- resistant enterococci. Emerging Infectious Dis 1998;4:37-47.

5. Japoni A, Farshad S, Ziyaeyan M, Ziaian S. Detection of Van-positive and negative vancomycin resistant enterococci and their antimicrobial susceptibility patterns to the newly introduced antibiotics. Pak J Biol Sci 2009; 12: 844-51.

6. Dutka-Malen S, Evers S, Courvalin P. Detection of glycopeptide resistance genotypes and identification to the species level of clinically relevant enterococci by PCR. J Clin Microbiol 1995; 33: 24-7.

7. Gordon S, Swenson JM, Hill BC, Pigott NE, Facklam RR, Cooksey RC et al. Antimicrobial susceptibility patterns of common and unusual species of enterococci causing infections in the United States. Enterococcal Study Group. J Clin Microbiol 1992; 30: 2373-8. 
8. Prakash VP, Rao SR, Parija SC. Emergence of unusual species of enterococci causing infections, South India. BMC Infect Dis 2005; 5(1): 14.

9. Citron DM, Edelstein MA, Garcia LS, Roberts GD, Thomson RB, Washington JA. Cultivation and isolation of viable pathogens. In: Baron EJ, Peterson LR, Finegold SM editors. Bailey \& Scott's Diagnostic Microbiology. $9^{\text {th }}$ ed. Missouri: Mosby-Year Book, Inc.; 1994. p. 79-96.

10. Berkeley RCW, Bock E, Boone DR, Brenner DJ et al. Gram Positive Cocci. In: Holt JG, Krieg NR, Sneath PHA, Staley JT, Williams ST editors. Bergey's Manual of Determinative Bacteriology. $9^{\text {th }}$ ed. Maryland: Williams \& Wilkins; 1994. p. 527-58.

11. Barrow GI, Feltham RKA. Characters of gram positive bacteria. In: Barrow GI, Feltham RKA editors. Cowan and Steel's manual for the identification of medical bacteria. $3^{\text {rd }}$ ed. Cambridge: Cambridge University press 1993. p. 59-68.

12. Clinical and Laboratory Standards Institute. Performance Standards for Antimicrobial Disk Susceptibility Tests. $9^{\text {th }}$ ed. Approved Standard. Wayne, PA: Clinical and Laboratory Standards Institute, 2006. (CLSI document no. M2-A9).

13. Moellering RC Jr. Enterococcus species, Streptococcus bovis and Leuconostoc species. In Mandell GL, Bennett JE, Dolin R editors. Mandell, Douglas and Bennett's Principles and Practice of Infectious Diseases. $4^{\text {th }}$ ed. Tokyo: Churchil Livingstone; 1995. p. 1826-35.

14. Centers for Disease Control: Nosocomial enterococci resistant to vancomycin-United States 1989-1993. MMWR Morbid Mortal Wkly Rep 1993; 42: 597-9.

15. Murray BE. Enterococci. In: Gorbach SL, Bartlett JG, Blacklow NR, editors. Infectious Diseases. $2^{\text {nd }}$ ed. Pennsylvania: WB Sounders; 1998. p. 1723-30.

16. McCarthy AE, Victor G, Ramotar K, Toye B. Risk factors for acquiring ampicillin resistant enterococci and clinical outcomes at a Canadian tertiary-care hospital. J Clin Microbiol 1994; 32 (11): 2671-6.

17. Low DE, Keller N, Barth A, Jones RN. Clinical Prevalence, Antimicrobial Susceptibility, and Geographic Resistance Patterns of Enterococci: Results from the SENTRY Antimicrobial Surveillance Program, 1997-1999. CID 2001; 32 (Suppl 2): S133-S145.
18. Udo EE, Sweih NA, Phillips OA, Chugh TD. Species prevalence and antibacterial resistance of enterococci isolated in Kuwait hospitals. J Med Microbiol 2003; 52: 163-8.

19. Mathur P, Kapil A, Chandra R, Sharma P, Das Bimal. Antimicrobial resistance in Enterococcus faecalis at a tertiary care centre of northern India. Indian J Med Res 2003; 118: 25-8.

20. Moellering RC Jr. Infections due to group D streptococci. Infect Dis Rev 1981; 6: 1-17.

21. Morrison AJ Jr, Wenzel RP. Nosocomial urinary tract infections due to Enterococcus; ten years' experience at a university hospital. Arch Intern Med 1986; 146: 1549-51.

22. Warren JW, Tenney JH, Hoopes JM. A prospective microbiologic study of bacteruria in patients with chronic indwelling urethral catheters. J Infect Dis 1982; 146: 719-23.

23. Vandamme $P$, Vercauteren E, Lammenns C, Pensart N, Ieven M, Pot B et al. Survey of enterococcal susceptibility patterns in Belgium. J Clin Microbiol 1996; 34: 2572-6.

24. Desai PJ, Pandit D, Mathur M, Gogate A. Prevalence, identification and distribution of various species of enterococci isolated from clinical specimens with special reference to urinary tract infection in catheterized patients. Indian J Med Microbiol 2001; 19: 132-7.

25. Marcus N, Peled N, Yagupsky. Rapid increase in the prevalence of antimicrobial drug resistance among enterococcal blood isolates in southern Israel. Eur J Clin Microbiol Infect Dis 1997; 16: 913-5.

26. Coleri A, Cokmus C, ozcan B, Akcelik M, Tukul C. Determination of antibiotic resistance plasmids of clinical Enterococcus species. J Gen Appl Microbiol 2004; 50: 213-19.

27. Azevedo PA, Dias CAG, Lemos SK, Bittencourt JAF, Teixera LM. Antimicrobial susceptibility among Enterococcus isolates from the city of Porto Alegre, RS, Brazil. Braz J Microbiol 2004; 35: 199-204.

28. Acar JF, Buu-Hoi AY. Resistance patterns of important Gram-positive pathogens. J Antimicrob Chemother 1988; 21: 41-7.

29. Perry, D. J., Ford, M. \& Gould, F. K. (1994). Susceptibility of enterococci to ciprofloxacin. J Antimicrob Chemother 1994; 34: 297-8.

30. Abdulla FE, Abdulla EM. Antibiotic options for Enterococcus faecalis infections. Pak J Med Sci 2006; 22(3): 286-90. 